\title{
Article \\ The Effectiveness of Ecklonia Cava Kjellman Extract in Improving Menopausal Syndrome in Osteoporosis and Depression
}

\author{
Hyun Yang, Hye Jin Kim and Hye Won Lee *(D)
}

check for updates

Citation: Yang, H.; Kim, H.J.; Lee, H.W. The Effectiveness of Ecklonia Cava Kjellman Extract in Improving Menopausal Syndrome in Osteoporosis and Depression. Appl. Sci. 2021, 11, 5315. https://doi.org/ 10.3390/app11125315

Academic Editor: Redha Taiar

Received: 25 April 2021

Accepted: 3 June 2021

Published: 8 June 2021

Publisher's Note: MDPI stays neutral with regard to jurisdictional claims in published maps and institutional affiliations.

Copyright: (c) 2021 by the authors. Licensee MDPI, Basel, Switzerland. This article is an open access article distributed under the terms and conditions of the Creative Commons Attribution (CC BY) license (https:/ / creativecommons.org/licenses/by/ $4.0 /)$.
Herbal Medicine Research Division, Korea Institute of Oriental Medicine (KIOM), 1672 Yuseong-daero, Yuseong-gu, Daejeon 34054, Korea; hyunyang@kiom.re.kr (H.Y.); kimhyejin43@kiom.re.kr (H.J.K.)

* Correspondence: hwlee@kiom.re.kr; Tel.: +82-42-868-9506; Fax: +82-42-868-9626

\begin{abstract}
Ecklonia cava (EC) is a natural material commonly used to decrease swelling, allergy, cancer, and sleep issues. Using EC has been reported to regulate hormones during ovarian failure in an aromatase inhibition rodent model. The aim of this study was to investigate EC's benefits on ovariectomized female mice. Hormone replacement therapy is beneficial in menopause, but the risk of side effects increases. In the present study, alkaline phosphatase (ALP) activity and tryptophan hydroxylases (TPHs) expression were studied after the EC extracts were incorporated as elemental, phloroglucinol, eckol, dieckol, 6,6'-biekcol, and 8,8'-bieckol. In this in vivo study, the following seven groups of 10-week-old Balb/c female mice were evaluated over 8 weeks: normal mice (Sham), ovariectomized mice (OVX), ovariectomized and restraint stressed mice (OVX $+\mathrm{R})$, ovariectomized and $17 \beta$-estradiol-treated mice $(\mathrm{OVX}+\mathrm{R}+\mathrm{E} 2)$, ovariectomized and fluoxetine-treated mice $(\mathrm{OVX}+\mathrm{R}$ + E2), and ovariectomized and EC-extract-treated mice (OVX + R + EC150 or OVX + R + EC300). The serum lipid profile, bone loss, and depressive symptoms were investigated in an ovariectomized and restraint-stressed mice model. In the in vitro models, ALP activity was dose-dependently upregulated by EC, including phloroglucinol, eckol, dieckol, 6,6'-biekcol, and 8,8' -bieckol, in RBL-2H3 cells. The transcripts of TPH1 and TPH2 were induced by EC and/or its elements (phloroglucinol, eckol, dieckol, 6,6'-biekcol, and 8,8'-bieckol) in RBL-2H3 cells. The re-uptake activity of serotonin (5-HT) was also decreased by EC and its ingredients such as phloroglucinol, eckol, dieckol, 6,6'-biekcol, and $8,8^{\prime}$-bieckol. In the models, the serum cholesterol and triglyceride levels were downregulated in OVX $+\mathrm{R}$ mice by EC treatment. The bone mineral density (BMD) was determined in EC-treated groups, and the bone metabolism markers, CTX and osteocalcin, were also reduced to normal levels. The depression experiments revealed that the immobility time was shortened in the forced-swimming test in OVX + R mice. Moreover, the serum serotonin level was promoted by EC treatment in OVX $+\mathrm{R}$ mice. These results showed that EC extract inhibits bone loss and depressive symptoms in a menopausal mouse model by modulating bone metabolism markers (CTX and osteocalcin) and serotonin level in OVX + R mice.
\end{abstract}

Keywords: Ecklonia cava; menopausal syndrome; ovariectomy; serotonin; osteoporosis

\section{Introduction}

During menopause, low estrogen levels can lead to various health problems such as hot flashes, sleep issues, joint pain, circulation disorder, bone loss, and depression [1,2]. Estrogen is considered to benefit various organs such as the heart, brain, blood, and uterus, as well as bone resorption via reduction in osteoclastic activity or production of osteoblastic activity [1,2]. Estrogen also plays an important role in the serotonergic system, where it balances mood through regulation [3]. Estrogen regulates bone formation, maturity, and metabolism in both women and men [4-6]. In menopause, a low estrogen level leads to increased modification rates due to an imbalance between bone resorption by osteoclasts and osteogenesis by osteoblasts [6]. This condition is linked with decreased BMD, which 
leads to an increased risk of fracture. Aromatase deficiency (owing to mutations in the cytochrome P450 subfamily 19 (CYP19) gene) leads to lessened BMD, delayed epiphysis, and decreased patient height. Bone loss was also experimentally noted in aromatase knockout mice [7]. Estrogen affects dopaminergic neurotransmission through mechanisms including synthesis, release, rotation, and degradation [8]. Estrogen has potent serotonin regulatory properties at the neurotransmitter synthesis level through tryptophan hydroxylase regulation $[9,10]$. Estrogen's effect on serotonin expression is also considered to modify the treatment duration in receptor subtypes, brain regions, and estrogen therapy cases $[9,10]$. Estrogen administration has been linked with increased tryptophan hydroxylase transcripts such as TPH1 and TPH2 [11-13].

Ecklonia cava Kjellman (EC) is a marine-brown-colored alga found in the seaside and oceans off of Korea. It is used as a therapeutic herbal agent in the form of seanol, an extract. Its components include phloroglucinol, eckol, dieckol, 6,6'-biekcol, and 8, $8^{\prime}$ bieckol, and other common components such as sterol derivatives [14-16]. The health benefits and chemistry of EC have been previously investigated, revealing its role in dietary supplements and treatments. Per previous studies, EC has antioxidant, anti-inflammatory, anti-diabetic, and anti-cancer properties [14-17]. EC has long been one of the ingredients used in many foods in Korea. EC has other benefits such as promoting hair growth through topical application and prevention of hair loss due to androgen [15].

In our previous study, EC and its ingredients of eckol, dieckol, 6,6'-dieckol, 8,8'-dieckol, and phloroglucinol were quantified using UHPLC-Triple-Q-MS/MS. Furthermore, EC was found to regulate hormonal disturbance among women with ovarian disease that induces estrogen deficiency through aromatase inhibition in the rodent model. EC effectively prevented the creation of dehydroepiandrosterone and its monitoring led to reduction in the blood androgen level, resulting in the alleviation of ovarian failure symptoms. However, as a consequence of confirming the expression in the pS2 gene used as an estrogen-active transcript marker, no estrogen-like effect was noted [18].

Recently, the efficacy of EC therapy on various menopause symptoms was studied in ovariectomized and restraint-stressed mice. Ovariectomy is a commonly used model to investigate menopausal symptoms due to the lack of ovarian hormones such as estrogen and progesterone. In the present study, a mouse model of ovariectomy and restraint stress was used to determine whether EC improves the serum lipid profile, bone loss, and depression in the menopausal mouse model. To add insight into the interaction of EC with bone metabolism and/or the serotonergic system through ALP, CTX, osteocalcin, PINP, TPHs, and 5-HT activities, reuptake was studied in in vitro and in vivo models. This mouse model was also used to study whether EC balances serum serotonin level and immobility time in a restraint-stressed mouse model.

\section{Materials and Methods}

\subsection{Preparation of E. cava Extract and Major Constituents}

Ecklonia cava Kjellman (EC), collected from Jeju Island, South Korea, was obtained from a global herbal medicine store in Jungwoo-Dang (Korea). Briefly, dried EC (5 kg) was extracted with $75 \mathrm{~L}$ of water for $3 \mathrm{~h}$, refluxing at $101 \pm 1{ }^{\circ} \mathrm{C}$, which was then filtered. To obtain EC powder, the extract was condensed and lyophilized in a freeze-dryer. The final yield of the EC extract was $11.46 \% w / w(573.01 \mathrm{~g})$. The plants were deposited in the Herbal Medicine Research Division of Korea Institute of Oriental Medicine (KIOM) in Daejeon, Korea (voucher specimen KIOM H 160150). The five compounds of major constituents in EC extracts, phloroglucinol, eckol, dieckol, 6,6'-biekcol, and 8,8'-bieckol, were provided by the National Development Institute of Korean Medicine (NIKOM), Gyeongsan-si, Korea.

\subsection{Cell Culture and Reagents}

MC3T3-E1 cells were purchased from the American Type Culture Collection (Gaithersburg, MD, USA) and cultured in MEM- $\alpha$ (PS; Gibco) containing $10 \%$ fetal bovine serum (FBS; Thermo Fisher Scientific, Waltham, MA, USA) with $1 \%$ penicillin and streptomycin. 
The rat basophilic leukemia cell line, RBL-2H3. was purchased from ATCC and cultured in MEM- $\alpha$ with $10 \%$ fetal bovine serum, $1 \%$ penicillin and streptomycin. ASP (4-Di-1-ASP (4-(4-(dimethylamino)styryl)- $N$-methylpyridinium iodide) was purchased from Invitrogen (Carlsbad, CA, USA); lipopolysaccharide (LPS) and fluoxetine were purchased from SigmaAldrich (St. Louis, MO, USA). All agents were developed in dimethyl sulfoxide (DMSO) and diluted in fresh medium.

\subsection{Cell Viability}

Cell viability was analyzed using a CellTiter 96 AQueous One solution Cell Proliferation Assay (Promega, WI, USA). A total of $1 \times 10^{3}$ cells were plated on 96-well plates and treated with TC and five compounds at different concentrations. After 48 and $72 \mathrm{~h}$, each well was treated with $20 \mu \mathrm{L}$ of MTS solution and incubated for $1 \mathrm{~h}$. Optical density was determined by calculating the absorbance at $490 \mathrm{~nm}$ (Synergy HTX Multi-Mode Reader; BioTeK, Winooski, VT, USA).

\subsection{ALP Assay}

MC3T3-E1 was seeded at $3 \times 10^{3}$ cells / well in 24-well plates, which were then cultured with $50 \mu \mathrm{g} / \mathrm{mL}$ ascorbic acid, $10 \mu \mathrm{M}$ dexamethasone, and $5 \mathrm{mM}$ b-glycerophosphate in the complete MEM- $\alpha$ media, with EC and each of the five components of EC. After 5 days, ALP activity was measured following the manufacturer's instructions (Abcam, Cambridge, UK). The optical density value was measured at $405 \mathrm{~nm}$ (Synergy HTX Multi-Mode Reader; BioTeK, Winooski, VT, USA).

\subsection{Reverse-Transcription and Real-Time PCR}

Total RNA was isolated using an RNeasy Mini Kit (Qiagen, Hilden, Germany) and cDNA was synthesized with $1 \mu \mathrm{g}$ of total RNA using an Invitrogen SuperScript III cDNA Synthesis Kit (Thermo Corporation, MA, USA) per the manufacturer's instructions. cDNA was amplified using Premix ExTaq (TaKaRa, Shiga, Japan) with SYBR Premix EX Taq (TaKaRa, Shiga, Japan) using an ABI PRISM 7500HT Sequence Detection System (Applied Biosystems). Primer was synthesized using Macrogen Inc. (Seoul, Korea). GAPDH expression was used as a control and the following custom-designed primers: for GAPDH, 5'-TCTCCTGCGACTTCAACA-3' $3^{\prime}$-CTGTAGCCGTATTCATTGTC-5': for TPH1, 5' ${ }^{\prime}$-ACCATCTTCCGAGAGCTGAA-3' ${ }^{\prime} 3^{\prime}$-GATGGAAAACCCTGTGCGTT-5' : for TPH2, 5' -ATCCCAAGTTTGCTCAGTTTT-3' $3^{\prime}$-GATGGACGAAAGTAACCCTG-5' : for SERT, 5' -AACTGGCAGAAACTCTTGGA-3', $3^{\prime}$-GAAGATGACGAA GCCAGAGA-5'

\subsection{Experimental Animals and Treatments}

Female Balb/c mice ( 5 weeks old, weight 15-20 g) were procured from Dooyeol Biotech Inc. (Seoul, Korea) and left to adapt to laboratory conditions (temperature: $20 \pm 2{ }^{\circ} \mathrm{C}$, relative humidity: $45 \pm 5 \%$, light/dark cycle: $12 \mathrm{~h}$ ) for 1 week. After 1 week of acclimatization at the experimental animal center of the Korea Institute of Oriental Medicine, animals were subjected to anesthesia using Avertin, and the skin was adjusted to the left and right to remove the ovary (ovariectomy (OVX)). A mouse model of menopausal depression was established by inducing symptoms for 8 weeks and providing a feeling of depression by applying restraint stress $(\mathrm{R})$ for $1 \mathrm{~h}$ a day from $7-8$ weeks after surgery. The mice $(n=56)$ were divided into seven groups ( $n=8$ vehicle group, $n=8 \mathrm{OVX}$ group, $n=8 \mathrm{OVX}+\mathrm{R}$ group, $n=8 \mathrm{OVX}+\mathrm{R}+$ fluoxetine $(10 \mathrm{mg} / \mathrm{kg})$ group, $n=8 \mathrm{OVX}+\mathrm{R}+\mathrm{E} 2(10 \mu \mathrm{g} / \mathrm{kg})$ group, $n=8$ $\mathrm{OVX}+\mathrm{R}+\mathrm{EC} 150 \mathrm{mg} / \mathrm{kg} /$ day group, and $n=8 \mathrm{OVX}+\mathrm{R}+\mathrm{EC} 300 \mathrm{mg} / \mathrm{kg} /$ day group), including positive controls using $\mathrm{E} 2$ and fluoxetine. All animal experimental procedures approved by the Ethics Committee of Korea Institute of Oriental Medicine (Approval No. 17-094; Daejeon, Korea). 


\subsection{5-HT Uptake Assay}

On day 1 , RBL-2H3 cells were seeded in 24-well plates at a density of $5 \times 10^{5}$; on day 2 , the medium was replaced with serum-free medium, followed by incubation for $4 \mathrm{~h}$ at $37^{\circ} \mathrm{C}$. Following this, the medium was removed and the cells were washed thrice in PBS. Next, they were incubated with a medium containing $1 \mathrm{mM}$ ASP and were dissolved in DMSO at $37^{\circ} \mathrm{C}$ for $1 \mathrm{~h}$ in the dark. The ASP-containing medium was removed and the cells were washed thrice with PBS. The fluorescence density was measured using a multi-fluorescent microplate reader (Spectra-Max Paradigm Multi-Mode Microplate Reader; molecular devices, Sunnyvale, CA, USA) at $\lambda \mathrm{ex}=475 \mathrm{~nm}$ and $\lambda \mathrm{em}=605 \mathrm{~nm}$.

\subsection{Serum Serotonin Analysis}

Blood samples were obtained directly from the inferior vena cava using a $1 \mathrm{~mL}$ syringe at the end of the experiment. Serum was acquired by centrifugation at $4000 \times g$ for $10 \mathrm{~min}$ and was stored at $-70{ }^{\circ} \mathrm{C}$ until use. Serum serotonin levels were measured using a Serotonin ELISA kit (Abnova; Taipei, Taiwan) following the instructions provided.

\subsection{BMD Analysis}

After the femur was fixed, it was washed with PBS one day before bone density measurement and was stored. The BMD, percent bone volume (BV/TV), trabecular (Tb) separation (Sp) were measured by micro-CT (Bruker, Kontich, Belgium). Carboxy-telpeptide cross-links of type I collagen (CTX), osteocalcin, and procollagen type 1 amino-terminal propeptide (PINP) were measured using an ELISA kit (Biomatik, ON, Canada).

\subsection{Statistical Analysis}

The data are presented as means \pm SD. Paired Student's $t$-tests were used to compare each group or one-way ANOVA with Tukey's multiple comparison tests using PRISM software (v7.0; Graph Pad, CA, USA). $p$ values of $<0.05$ were considered statistically significant.

\section{Results}

\subsection{EC Improved Animal Condition}

To determine whether EC ( 150 or $300 \mathrm{mg} / \mathrm{kg} /$ day) treatments could improve menopause symptoms in the ovariectomized mice, the mice were orally administered with E2, fluoxetine, and EC. All experimental groups included in the ovariectomy animal model showed significant weight gain compared with vehicle groups, but high-concentration treatment groups showed significant weight loss compared with ovariectomy groups. The uterus weight was significantly higher in the vehicle group $(92.90 \pm 35.50 \mathrm{mg})$ than in the OVX group (32.95 $\pm 7.14 \mathrm{mg})$ and a similar uterine weight as the vehicle group was recorded for the OR + E2 group (139.11 $\pm 31.18 \mathrm{mg})$. The intraperitoneal fat weight was considerably higher in the OVX $(50.38 \pm 16.76 \mathrm{mg})$, OR $(79.55 \pm 15.24 \mathrm{mg})$, and OR + Fluoxetine $(86.34 \pm 22.22 \mathrm{mg}$ ) groups compared with the vehicle group (35.29 $\pm 8.09 \mathrm{mg})$; however, the fat weight was lower than normal levels in the OR + E2 group (49.49 $\pm 10.54 \mathrm{mg})$. Both low and high concentrations of EC extract (low: $59.01 \pm 19.11 \mathrm{mg}$, high: $57.26 \pm 9.61 \mathrm{mg}$ ) were produced lower intraperitoneal fat weight than those of the OR group $(79.55 \pm 15.24 \mathrm{mg})$ and no concentration-dependent decrease was observed. Blood LDL-cholesterol was observed to be high in the OVX $(13.90 \pm 1.93 \mathrm{mg} / \mathrm{dL})$ and OR group $(13.80 \pm 3.08 \mathrm{mg} / \mathrm{dL})$, and lowest in the high-concentration EC extract treatment group $(5.38 \pm 2.67 \mathrm{mg} / \mathrm{dL})$. In terms of HDL-cholesterol, no considerable change was noted in either the control or treatment groups. In terms of total-cholesterol, the cholesterol blood level increased by ovariectomy was lowered using the EC extract, similar to the tendency of LDL-cholesterol (Figure 1). 

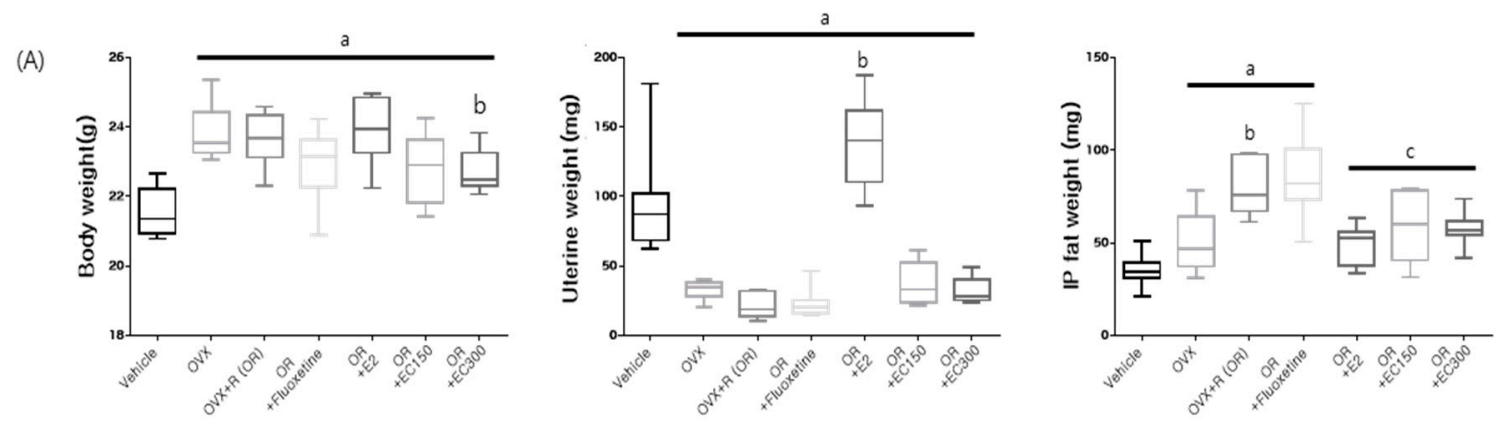

(B)
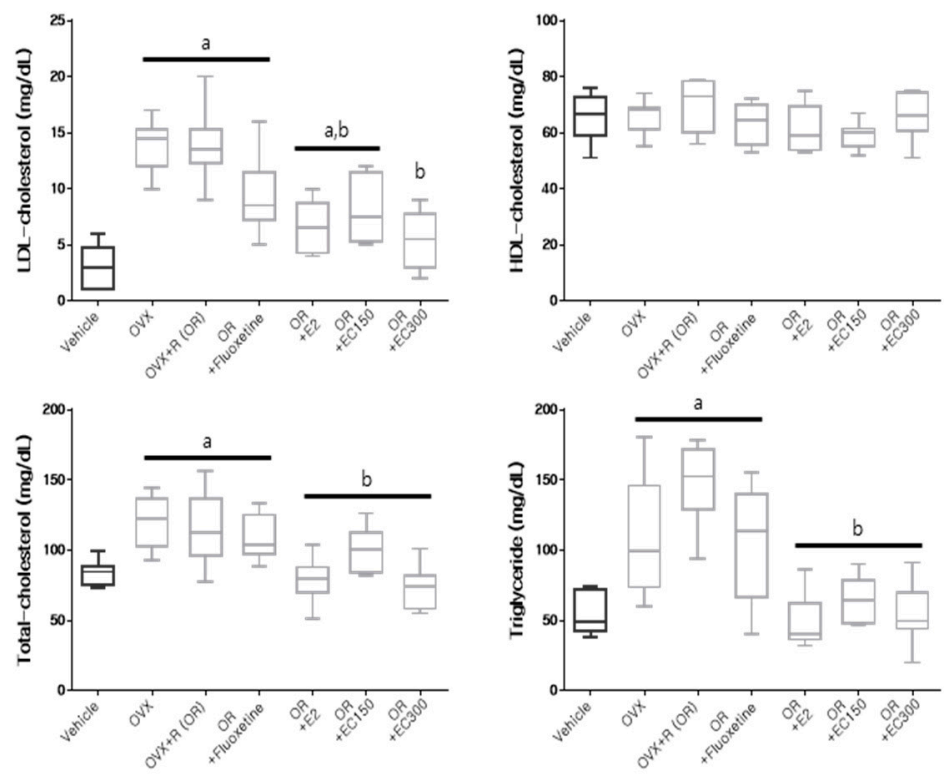

Figure 1. Physiological changes during the experiment. After 8 weeks since ovariectomy, EC extract was administered into mice by oral treatment every day for 8 weeks. (A) Body weight, uterine weight, and intraperitoneal (IP) fat weight. (B) Serum levels of LDL, HDL, total cholesterol, and triglycerides were measured using a competitive ELISA kit. ${ }^{\text {a }} p<0.05$ vs. vehicle group. ${ }^{\mathrm{b}} p<0.05$ vs. OVX. ${ }^{\mathrm{c}} p<0.05$ vs. OR.

\subsection{EC Enhances MC3T3-E1 Osteoblast Differentiation}

We aimed to determine if the EC extract and the five constituents would promote MC3T3-E1 osteoblast differentiation. Treatment with 10, 50, and $100 \mu \mathrm{g} / \mathrm{mL}$ of EC extract significantly increased ALP activity, $(0 \mu \mathrm{g} / \mathrm{mL}: 1 \pm 0.01,10 \mu \mathrm{g} / \mathrm{mL}: 1.09 \pm 0.03,50 \mu \mathrm{g} / \mathrm{mL}$ : $1.16 \pm 0.09$ and $100 \mu \mathrm{g} / \mathrm{mL}: 1.32 \pm 0.09$ fold), and the five constituents (phloroglucinol, eckol, dieckol, 6,6'-bieckol, and 8,8'-bieckol) also increased ALP activity compared with the control (Figure 2). Briefly, the ALP activity levels in treatment groups, phloroglucinol $(0 \mu \mathrm{M}: 1 \pm 0.07,1 \mu \mathrm{M}: 1.84 \pm 0.04,10 \mu \mathrm{M}: 1.85 \pm 0.03,20 \mu \mathrm{M}: 1.91 \pm 0.02$ and $50 \mu \mathrm{M}$ : $1.87 \pm 0.06$ fold), eckol $(0 \mu \mathrm{M}: 1 \pm 0.07,1 \mu \mathrm{M}: 1.82 \pm 0.04,10 \mu \mathrm{M}: 1.83 \pm 0.03,20 \mu \mathrm{M}$ : $1.87 \pm 0.03$ and $50 \mu \mathrm{M}: 1.96 \pm 0.03$ fold), dieckol $(0 \mu \mathrm{M}: 1 \pm 0.07,1 \mu \mathrm{M}: 1.84 \pm 0.01,10 \mu \mathrm{M}$ : $1.82 \pm 0.01,20 \mu \mathrm{M}: 1.87 \pm 0.03$ and $50 \mu \mathrm{M}: 1.81 \pm 0.04$ fold $), 6,6^{\prime}$-bieckol $(0 \mu \mathrm{M}: 1 \pm 0.07$, $1 \mu \mathrm{M}: 1.83 \pm 0.02,10 \mu \mathrm{M}: 1.86 \pm 0.02,20 \mu \mathrm{M}: 1.95 \pm 0.01$ and $50 \mu \mathrm{M}: 2.03 \pm 0.01$ fold), and 8, $8^{\prime}$-bieckol $(0 \mu \mathrm{M}: 1 \pm 0.07,1 \mu \mathrm{M}: 1.72 \pm 0.01,10 \mu \mathrm{M}: 1.8 \pm 0.01,20 \mu \mathrm{M}: 1.9 \pm 0.01$ and $50 \mu \mathrm{M}: 2.15 \pm 0.01$ fold), were significantly higher than control. 
(A)<smiles>Oc1cc(O)cc(O)c1</smiles>

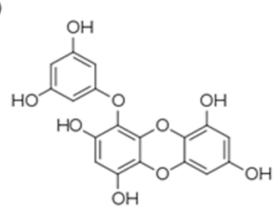

(C)

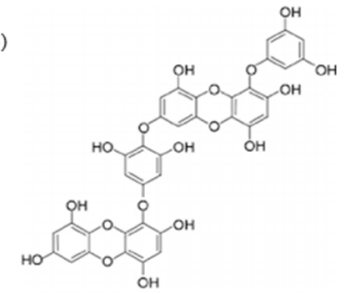<smiles>COc1cc(O)cc(Oc2c(O)cc(O)c(Oc3c(O)cc(O)c4c3Oc3c(O)cc(O)c(O)c3O4)c2Oc2c(O)cc(O)cc2O)c1</smiles>

(E)
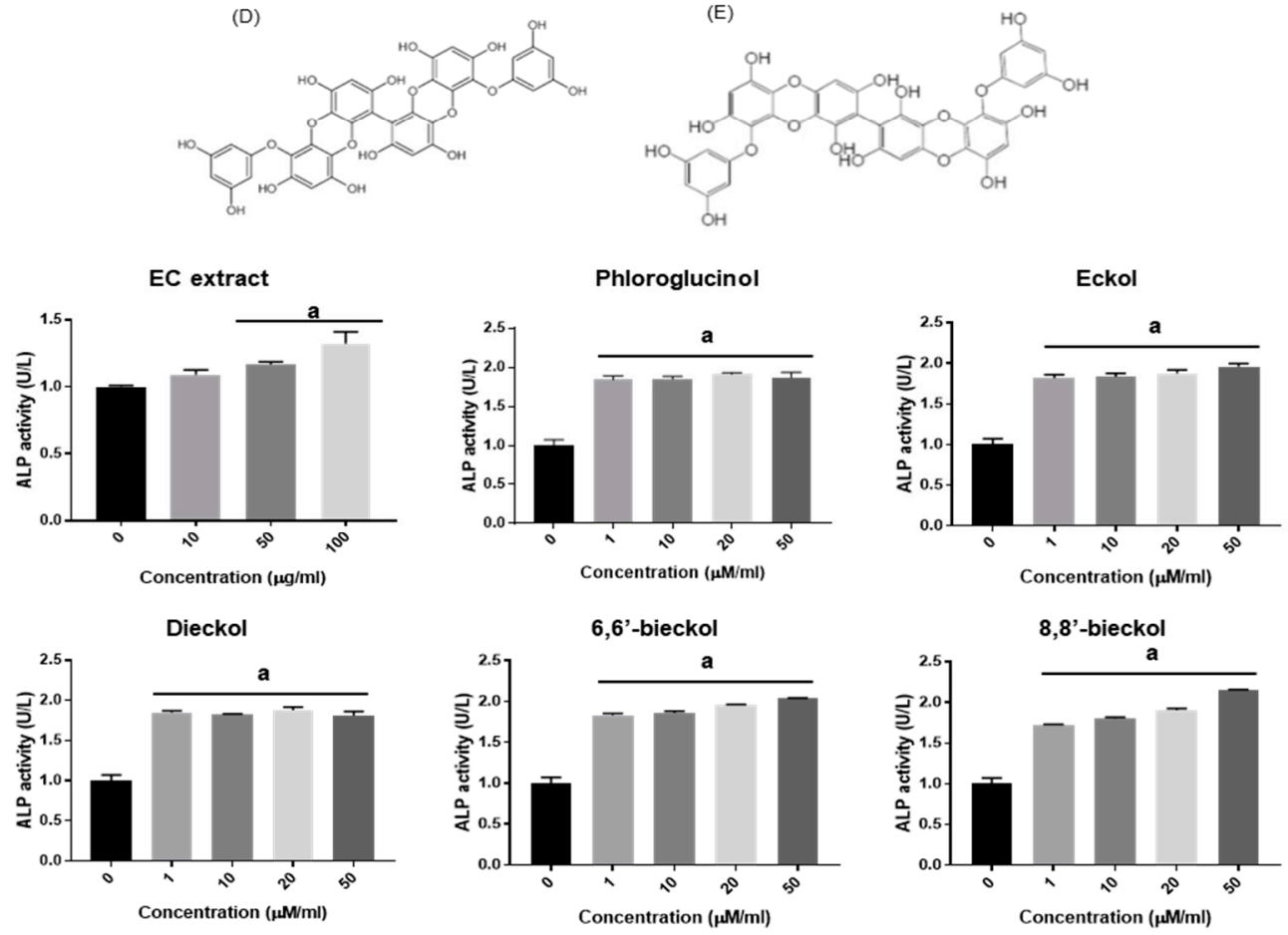

Figure 2. The chemical structures and effects of EC extract and its components ((A) phloroglucinol, (B) eckol, (C) dieckol, (D) 6,6'-biekcol, and (E) 8,8'-bieckol) on the ALP activity in MC3T3-E1 cells. EC extract, phloroflucinol, eckol, dieckol, $6,6^{\prime}$-biekcol, and 8,8'-bieckol were measured using a microplate reader at a wavelength of $405 \mathrm{~nm}$. ${ }^{\mathrm{a}} p<0.05 \mathrm{vs}$. the control group.

\subsection{Effect of EC on In Vivo Bone Formation}

The bone density of the OVX $\left(0.143 \pm 0.006 \mathrm{~g} / \mathrm{cm}^{3}\right)$, OR $\left(0.147 \pm 0.005 \mathrm{~g} / \mathrm{cm}^{3}\right)$, and $\mathrm{OR}+$ fluoxetine $\left(0.141 \pm 0.003 \mathrm{~g} / \mathrm{cm}^{3}\right)$ groups was decreased compared with the vehicle group $\left(0.239 \pm 0.013 \mathrm{~g} / \mathrm{cm}^{3}\right)$, and a significant increase was noted in the OR $+\mathrm{E} 2\left(0.177 \pm 0.014 \mathrm{~g} / \mathrm{cm}^{3}\right)$, $\mathrm{OR}+\mathrm{EC} 150\left(0.157 \pm 0.012 \mathrm{~g} / \mathrm{cm}^{3}\right)$, and OR $+\mathrm{EC} 300\left(0.185 \pm 0.020 \mathrm{~g} / \mathrm{cm}^{3}\right)$ groups. A notable difference was observed in the high-concentration treatment group compared with the lowconcentration EC-extract treatment group. This confirmed that the bone density improved depending on the concentration. BV/TV represents the proportion of trabecular bone in whole femur tissue; its observed trend was similar to that of BMD. The tendencies of Tb.Th and Tb.N were also observed as being similar to bone density; blood concentrations of CTX and osteocalcin, which are related to bone resorption, were significantly increased by ovariectomy. However, a decrease in the expression of CTX and osteocalcin was found in the E2-treated group, and a concentration-dependent significant reduction effect was established in the EC extract treatment group (Figure 3). 
(A)
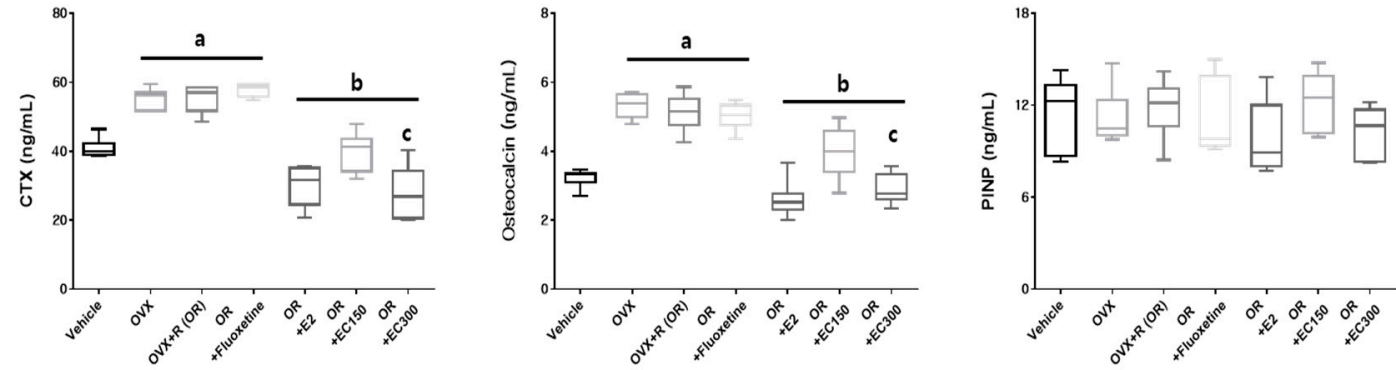

(B)

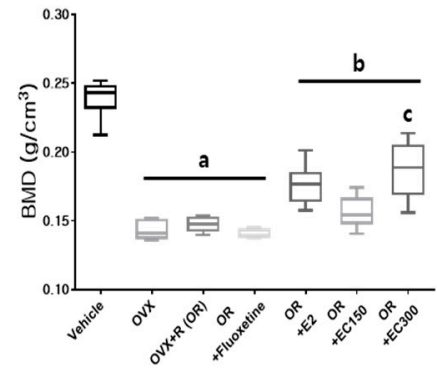

(E)

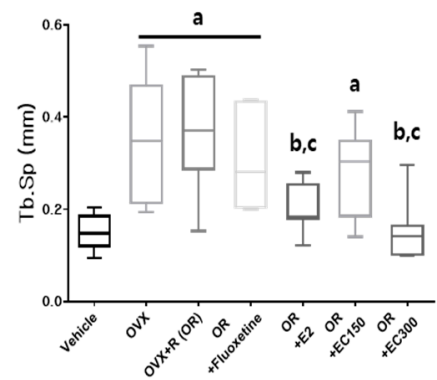

(C)

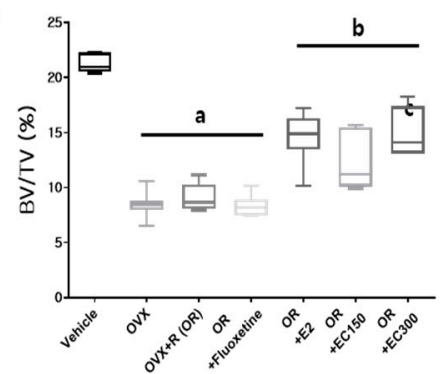

(F)

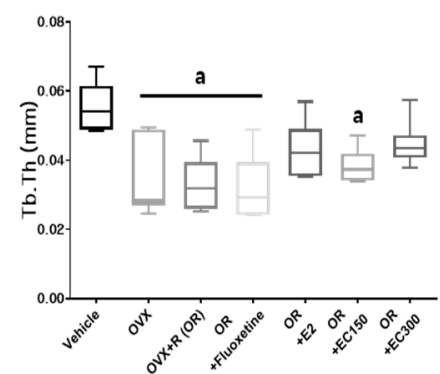

(D)

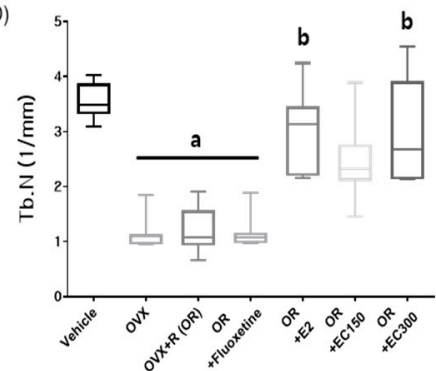

Figure 3. Effects of EC extract on the serum bone biomarkers and bone mineral density. Bone metabolism markers (A) CTX, osteocalcin, and PINP. (B) Bone mineral density (BMD), (C) percent bone volume (BV/TV), (D) trabecular separation (Tb.Sp), (E) trabecular thickness (Tb.Th), and (F) trabecular number (Tb.N) were photographed by micro-CT, and data were evaluated using analyzing software (CTan). ${ }^{a} p<0.05$ vs. vehicle group. ${ }^{b} p<0.05$ vs. OVX. ${ }^{c} p<0.05$ vs. OR.

\subsection{Effects of EC on TPH-1, TPH-2, and SERT mRNA Expression}

To determine the cytotoxicity effect of $\mathrm{EC}$, we used treatments with various concentrations of TC ranging from 1-1000 $\mathrm{\mu g} / \mathrm{mg}$ for $48,72 \mathrm{~h}$. As shown in Figure 4A, cell proliferation did not decrease in the presence of the TC. Figure $4 \mathrm{~B}-\mathrm{D}$ shows that the TPH1 mRNA expression level increased by about two times in the group treated with 50 and $100 \mu \mathrm{g} / \mathrm{mL}$ of EC extract compared with the untreated group. Phloroglucinol, eckol, dieckol, 6,6'-bieckol, and 8,8'-bieckol, the main components of EC, were found to be significantly higher in the treatment with $10 \mu \mathrm{g} / \mathrm{mL}$ concentration in all groups, except dieckol; however, in the case of phloroglucinol, depending on the concentration, the treatment concentration of $20 \mu \mathrm{g} / \mathrm{mL}$ also resulted in significantly higher cell proliferation. Similar to TPH1 mRNA expression, TPH2 mRNA expression showed an increase at a concentration of $10 \mu \mathrm{g} / \mathrm{mL}$. Phloroglucinol and 8, $8^{\prime}$-bieckol tended to show significantly increased expression. The mRNA expression of SERT was significantly higher in the $100 \mu \mathrm{g} / \mathrm{mL}$ of EC extract treatment group and a notable increase was observed with phloroglucinol and $8,8^{\prime}$-bieckol based on the concentration (Figure 4). 
(A)

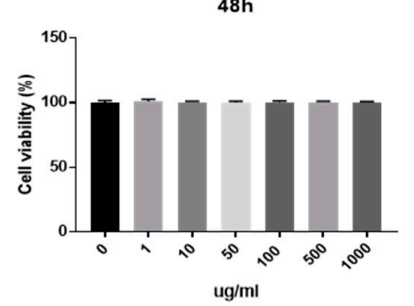

$72 \mathrm{~h}$

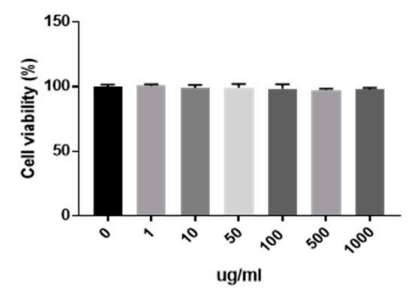

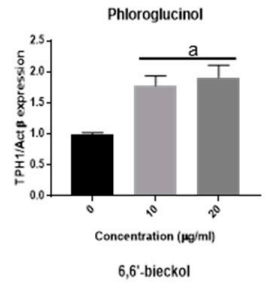
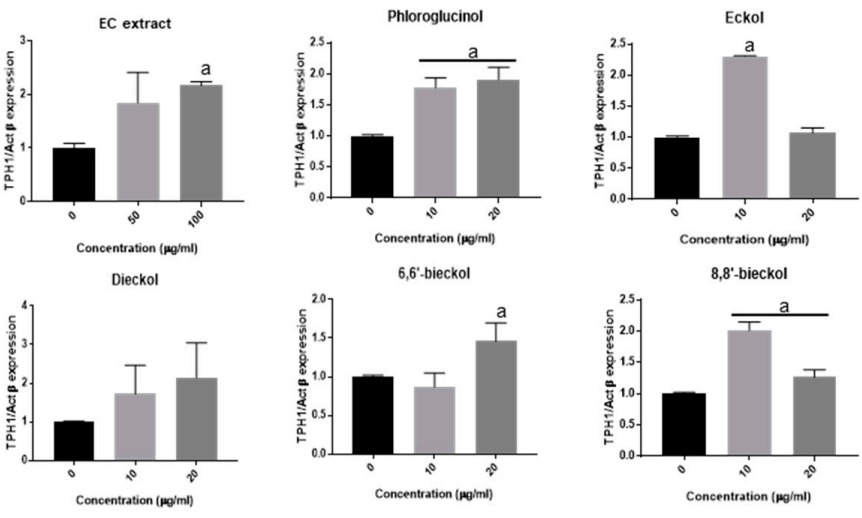

(C)
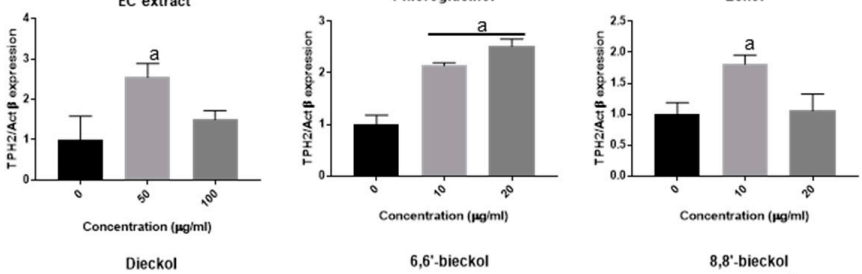

Dieckol
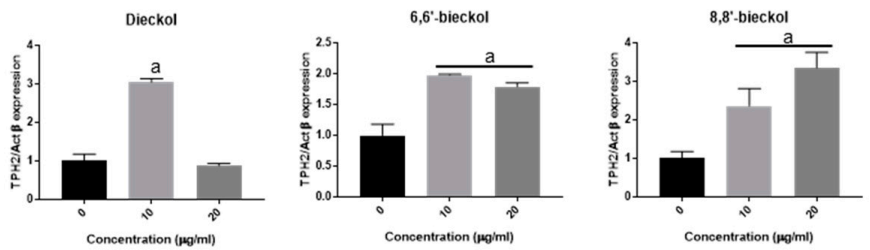

(D)
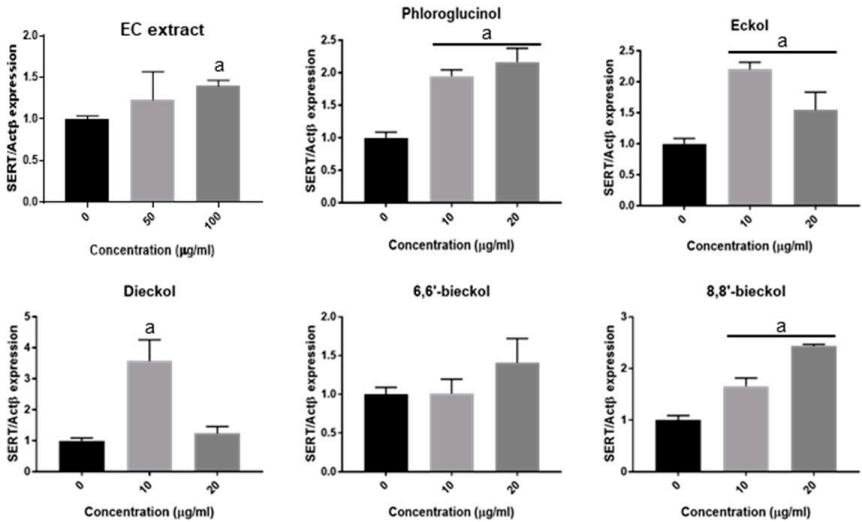

Figure 4. Cytotoxicity effect of EC on RBL-2H3 cells and the effect of EC and its major constituents on the mRNA expression of serotonin synthesis enzymes and serotonin transporter. (A) Cell viability of RBL-2H3 treated with various concentrations of each component for 48 and $72 \mathrm{~h}$. A total of $1 \times 10^{3}$ cells were plated into 96-well plates and then EC was added at different concentrations. After 48 and $72 \mathrm{~h}$, the cells were incubated with MTS for $3 \mathrm{~h}$. Absorbance was recorded at $490 \mathrm{~nm}$. (B-D) Comparison of serotonin-related mRNA expression levels between control condition (nontreated) or treated with EC for $48 \mathrm{~h}$. (B) TPH-1, (C) TPH-2, and (D) SERT mRNA expressions were tested using RT-PCR in the RBL-2H3 cell line. Experiments were conducted in triplicate and data are expressed as means \pm SD. ${ }^{a} p<0.05$ versus the control group. 


\subsection{Effects of EC on 5-HT Uptake by RBL-2H3 Cells}

To further investigate the effects of EC and the main elements of 5-HT uptake by RBL-2H3 cells, 5-HT uptake was studied by calculating SERT activities using the ASP fluorescent intensities in RBL-2H3 cells. LPS improves 5-HT uptake by stimulating SERT, which is important in depression [19], whereas fluoxetine reduces 5-HT uptake by behaving as an SSRI. LPS $(3 \mu \mathrm{g} / \mathrm{mL})$ was used as the negative control and fluoxetine $(10 \mu \mathrm{M})$, which is a well-known selective serotonin reuptake inhibitor, was the positive control. Finally, the results showed that 5-HT uptake was significantly lowered with EC treatment in a dose-dependent manner, similar to the effect of $10 \mu \mathrm{M}$ fluoxetine (Figure 5).
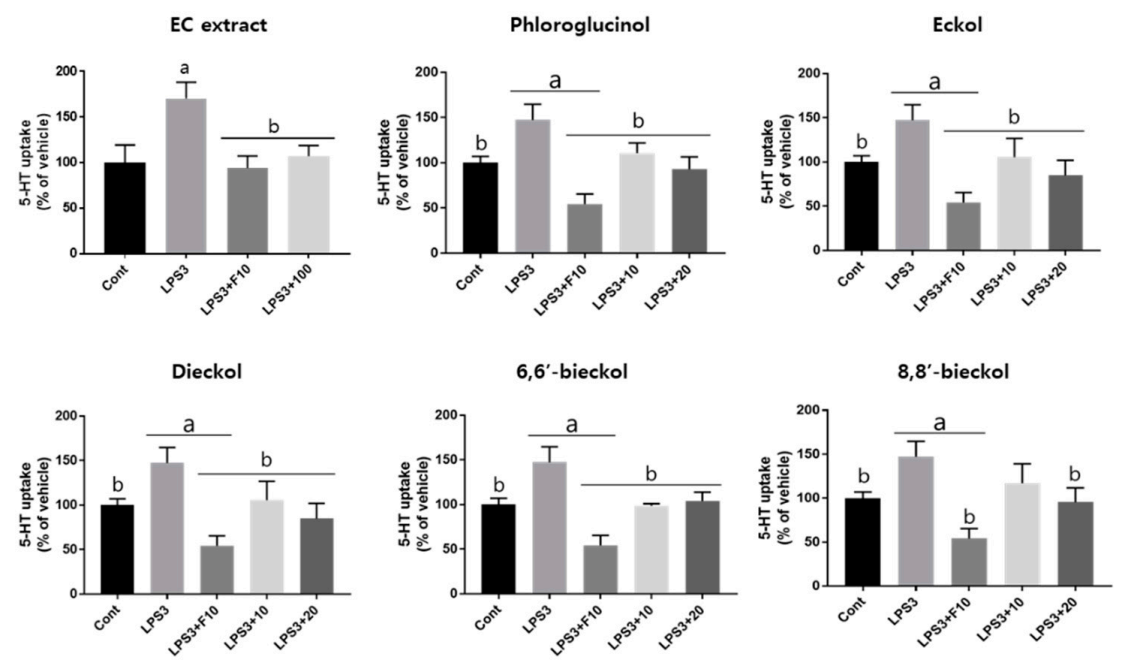

Figure 5. EC inhibited LPS-induced 5-HT uptake in RBL-2H3 cells. RBL-2H3 cells were seeded in a 24-well plate $\left(5 \times 10^{5}\right.$ cell/well) and treated with $3 \mu \mathrm{g} / \mathrm{mL}$ LPS, followed by treatment or absence of fluoxetine $(10 \mu \mathrm{M})$ and EC at different concentrations $(10$ or $20 \mu \mathrm{g} / \mathrm{mL})$ for $16 \mathrm{~h}$. Experiments were conducted in triplicate and data are expressed as means $\pm \mathrm{SD} .{ }^{\mathrm{a}} p<0.05$ versus control, ${ }^{\mathrm{b}} p<0.05$ versus LPS $3 \mu \mathrm{g} / \mathrm{mL}$.

\subsection{Serum Serotonin Level and Immobility Time}

During the forced swimming test, the increased immobility time compared with the vehicle group with OVX and OR was decreased significantly for the fluoxetine and E2treated groups. In the EC extract treatment group, the immobility time was lessened at both low and high concentrations, whereas the time decreased with high concentrations compared with the low concentration treatment group (Figure 6).

(A)

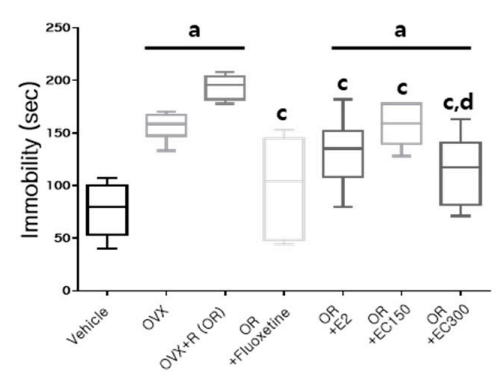

(B)

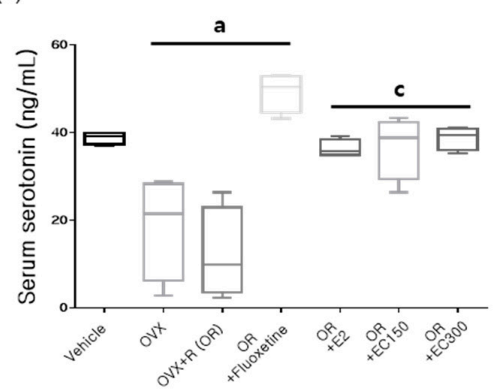

Figure 6. Effects of EC extract on the depressive symptoms and the serum serotonin level in an ovariectomized and restraint-stressed mice model. (A) Immobility time in forced swimming test; (B) the level of serum serotonin in the mouse model. ${ }^{\mathrm{a}} p<0.05$ vs. vehicle group. ${ }^{\mathrm{b}} p<0.05$ vs. OVX. ${ }^{\mathrm{c}} p<0.05$ vs. OVX + R. ${ }^{\mathrm{d}} p<0.05$ vs. OVX $+\mathrm{R}+\mathrm{EC} 150$. 


\section{Discussion}

Menopause is a medical condition that occurs in middle-aged women, characterized by uneven or inadequate estradiol levels and high levels of androgens [1,2]. Estrogen deficiency causes various health issues such as hot flashes, sleep disorders, joint pain, bone loss, and mood disturbances. Estrogen is known to benefit various types of cardiac, brain, bone, and mood disorders due to neurotransmitter transduction and regulation of osteoclastic and/or osteoblastic metabolism [7,20,21]. In this study, we found that orally administrated EC produces anti-bone loss and anti-depressive effects mediated by osteoblastic and/or osteoclastic activities and the serotonergic system in the forced swimming test in ovariectomized mice.

Bone is a complex tissue containing multiple cell types that are continuously renewed and repaired [6]. If bone resorption and formation are imbalanced, fractures are likely to occur during osteogenesis. In this study, an ovariectomy mouse was used to investigate the anti-osteoporotic effect of EC extract as a result of osteoporosis. The ovariectomized mice showed reduced bone mineral density throughout the body, which was alleviated by EC extract treatment. The treatment also increased bone-formation markers (ALP) in MC3T3-E1. Therefore, EC extract can be considered an osteogenesis reagent that prevents bone loss during in vivo ovarian dissection. Although the functions of osteoporosis are still unclear, they are probably linked with the availability and reduced effectiveness of bone growth factors such as ALP, CTX, and osteocalcin [22]. These three components play an important role in the bone formation and remodeling processes, which is documented by the stimulation of osteoblast cell differentiation or osteoclastic inactivation. In the present study, we observed that EC extract increased ALP and decreased CTX and osteocalcin, encouraging bone mineralization. Accordingly, the EC extract mediated part of bone formation by regulating ALP, CTX, and osteocalcin. An osteocalcin non-collagen protein contains 49 amino acids that are produced in osteoblasts. About $20 \%$ of synthetic osteocalcin is not contained in bones but passes into the bloodstream and is considered a bone-forming marker [23]. PINP is a circulating protein produced by osteoblasts during the synthesis of type-I collagen, serving as another osteogenic marker [22]. During bone resorption, type-I collagen CTX is released into the bloodstream and works as a bone resorption marker [22]. Our findings show, through experiments on mice, that the serum bone formation marker of osteocalcin as well as the bone resorption marker of CTX were reduced by EC treatment. Although body weight usually positively contributes to BMD, components linking bone metabolism to body mass have not been completely established. In general, it can be considered a passive action of body weight, a direct action of muscle, and an indirect action of measurement. In the current study, body weight decreased with high-dose EC treatment; however, the BMD recovered to normal levels, perhaps due to low blood cholesterol and intraperitoneal fat weight.

The findings also revealed that the EC extract treatment produced significant antidepressive symptoms effects during the forced swimming test. The result points to the possible contribution of the serotonergic system to the EC extract's role in increasing the blood level of serotonin in the body. The reason for this was also noted in the effect on 5-HT reuptake with EC treatment and the increased expression of the transcripts of TPH1 and TPH2. Low 5-HT1A binding potential has been noted in depressive patients in multiple forebrain regions, including the frontal cortex and the hippocampus [24,25]. Therefore, the function and expression of 5-HT receptors are important in inducing depression. The role of 5-HT receptors, including the antidepressant-like functions of several plants, involves producing properties of antidepressants such as tricyclic systems, selective serotonin reuptake inhibitors (SSRIs), and monoamine oxidase inhibitors (MAOis) [24-26]. Additionally, 5-HT receptors are necessary for SSRI antidepressants' effectiveness in both acute and chronic behavior models [24-26].

This aim of this study was to use the components of EC extract, such as phloroglucinol, eckol, dieckol, 6,6'-biekcol, and 8,8'-bieckol, to ascertain the regulation of ALP activity and THPs expression. Phloroglucinol is one of the spasmodic drugs commonly 
used for gastrointestinal pain and labor pain relief [27]. Dieckol, particularly, is known as the most abundant polyphenol in EC and has protected human endothelial cells under oxidative stress, dermal cancer, and lipid accumulation [28,29]. In addition, bieckol has been identified in previous studies for its anti-obese, hypoxic stress, anticancer, and antioxidant effects [30-33]. In the current study, we found that phloroglucinol, eckol, dieckol, 6,6'-biekcol, and 8,8' -bieckol induce ALP stimulation and inhibit 5-HT reuptake in in vitro models. The findings showed that phloroglucinol, eckol, dieckol, 6,6'-biekcol, and $8,8^{\prime}$-bieckol improve menopausal symptoms specifically in in vitro experiments; similar detailed studies will be conducted in future in vivo research.

\section{Conclusions}

In conclusion, the efficacy of EC extracts and its components in ovariectomized and restraint-stressed mice was examined in this research, finding effects including alleviating hypercholesterolemia, bone loss, and depressive symptoms in a menopausal mouse model upon EC treatment. As observed from the study results, EC may be a dependable therapeutic reagent for the treatment of menopausal disorders as it effectively controlled the levels of ALP, CTX, osteocalcin, and serum serotonin in a menopausal mouse model. In future studies, more detailed research will be conducted on the mechanisms of menopausal symptom relief using EC components.

Author Contributions: H.Y., H.J.K. and H.W.L. performed the research, analyzed the data, and wrote the manuscript; H.Y. performed in vivo experiments and data analysis; H.J.K. performed in vitro experiments and data analysis. All authors have read and agreed to the published version of the manuscript.

Funding: This work was supported by a grant from the Korea Institute of Oriental Medicine (grant no. KSN20134276 and KSN2021240).

Institutional Review Board Statement: Ethics approval was obtained from the Institutional Animal Care and Use Committee of Korean Institute of Oriental Medicine at Daejeon in Republic of Korea (approved no. 17-094).

Informed Consent Statement: Not applicable.

Data Availability Statement: All data generated or analyzed during the present study are included in this published article.

Conflicts of Interest: The authors declare that they have no competing interests.

\section{References}

1. Lobo, R.A. Serono Symposia USA. In Perimenopause; Springer: New York, NY, USA, 1997; p. 348.

2. Novi, J.M.; Ross, H.L. Perimenopause; Informa Healthcare: New York, NY, USA, 2009; p. 189.

3. Chojnacki, C.; Walecka-Kapica, E.; Klupinska, G.; Pawlowicz, M.; Blonska, A.; Chojnacki, J. Effects of fluoxetine and melatonin on mood, sleep quality and body mass index in postmenopausal women. J. Physiol. Pharmacol. 2015, 66, 665-671.

4. Biegon, A.; Alia-Klein, N.; Alexoff, D.L.; Fowler, J.S.; Kim, S.W.; Logan, J.; Pareto, D.; Preston-Campbell, R.; Wang, G.J.; Hildebrandt, T. Relationship of estrogen synthesis capacity in the brain with obesity and self-control in men and women. Proc. Natl. Acad. Sci. USA 2020, 117, 22962-22966. [CrossRef] [PubMed]

5. Pepine, C.J.; Nichols, W.W.; Pauly, D.F. Estrogen and different aspects of vascular disease in women and men. Circ. Res. 2006, 99, 459-461. [CrossRef] [PubMed]

6. Cauley, J.A. Estrogen and bone health in men and women. Steroids 2015, 99, 11-15. [CrossRef]

7. Mullis, P.E.; Yoshimura, N.; Kuhlmann, B.; Lippuner, K.; Jaeger, P.; Harada, H. Aromatase deficiency in a female who is compound heterozygote for two new point mutations in the P450arom gene: Impact of estrogens on hypergonadotropic hypogonadism, multicystic ovaries, and bone densitometry in childhood. J. Clin. Endocrinol. Metab. 1997, 82, 1739-1745. [CrossRef]

8. Joffe, R.T. Hormone treatment of depression. Dialogues Clin. Neurosci. 2011, 13, 127-138. [PubMed]

9. Amin, Z.; Canli, T.; Epperson, C.N. Effect of estrogen-serotonin interactions on mood and cognition. Behav. Cogn. Neurosci. Rev. 2005, 4, 43-58. [CrossRef]

10. Blum, I.; Vered, Y.; Lifshitz, A.; Harel, D.; Blum, M.; Nordenberg, Y.; Harsat, A.; Sulkes, J.; Gabbay, U.; Graff, E. The effect of estrogen replacement therapy on plasma serotonin and catecholamines of postmenopausal women. Isr. J. Med. Sci. 1996, 32, 1158-1162. 
11. Sanchez, R.L.; Reddy, A.P.; Centeno, M.L.; Henderson, J.A.; Bethea, C.L. A second tryptophan hydroxylase isoform, TPH-2 mRNA, is increased by ovarian steroids in the raphe region of macaques. Brain Res. Mol. Brain Res. 2005, 135, 194-203. [CrossRef]

12. Invernizzi, R.W. Role of TPH-2 in brain function: News from behavioral and pharmacologic studies. J. Neurosci. Res. 2007, 85, 3030-3035. [CrossRef]

13. Lopez-Narvaez, M.L.; Tovilla-Zarate, C.A.; Gonzalez-Castro, T.B.; Juarez-Rojop, I.; Pool-Garcia, S.; Genis, A.; Ble-Castillo, J.L.; Fresan, A. Association analysis of TPH-1 and TPH-2 genes with suicidal behavior in patients with attempted suicide in Mexican population. Compr. Psychiatry 2015, 61, 72-77. [CrossRef] [PubMed]

14. Yoon, J.Y.; Choi, H.; Jun, H.S. The Effect of Phloroglucinol, A Component of Ecklonia cava Extract, on Hepatic Glucose Production. Mar. Drugs 2017, 15, 106. [CrossRef]

15. Kang, J.I.; Kim, S.C.; Kim, M.K.; Boo, H.J.; Jeon, Y.J.; Koh, Y.S.; Yoo, E.S.; Kang, S.M.; Kang, H.K. Effect of Dieckol, a component of Ecklonia cava, on the promotion of hair growth. Int. J. Mol. Sci. 2012, 13, 6407-6423. [CrossRef] [PubMed]

16. Kang, N.J.; Koo, D.H.; Kang, G.J.; Han, S.C.; Lee, B.W.; Koh, Y.S.; Hyun, J.W.; Lee, N.H.; Ko, M.H.; Kang, H.K.; et al. Dieckol, a Component of Ecklonia cava, Suppresses the Production of MDC/CCL22 via Down-Regulating STAT1 Pathway in Interferongamma Stimulated HaCaT Human Keratinocytes. Biomol. Ther. 2015, 23, 238-244. [CrossRef] [PubMed]

17. Park, E.Y.; Choi, H.; Yoon, J.Y.; Lee, I.Y.; Seo, Y.; Moon, H.S.; Hwang, J.H.; Jun, H.S. Polyphenol-Rich Fraction of Ecklonia cava Improves Nonalcoholic Fatty Liver Disease in High Fat Diet-Fed Mice. Mar. Drugs 2015, 13, 6866-6883. [CrossRef]

18. Yang, H.; Lee, S.Y.; Lee, S.R.; Pyun, B.J.; Kim, H.J.; Lee, Y.H.; Kwon, S.W.; Suh, D.H.; Lee, C.H.; Hong, E.J.; et al. Therapeutic Effect of Ecklonia cava Extract in Letrozole-Induced Polycystic Ovary Syndrome Rats. Front. Pharmacol. 2018, 9, 1325. [CrossRef]

19. Zhu, C.B.; Lindler, K.M.; Owens, A.W.; Daws, L.C.; Blakely, R.D.; Hewlett, W.A. Interleukin-1 receptor activation by systemic lipopolysaccharide induces behavioral despair linked to MAPK regulation of CNS serotonin transporters. Neuropsychopharmacology 2010, 35, 2510-2520. [CrossRef]

20. Matsubara, K.; Harada, H.; Ando, N.; Watada, S.; Obara, H.; Matsumoto, K.; Kitagawa, Y. Estrogen deficiency attenuates neovascularization in a murine model of hindlimb ischemia. J. Surg. Res. 2012, 178, 1022-1028. [CrossRef]

21. Weitzmann, M.N.; Pacifici, R. Estrogen deficiency and bone loss: An inflammatory tale. J. Clin. Investig. 2006, 116, 1186-1194. [CrossRef]

22. Szulc, P.; Naylor, K.; Hoyle, N.R.; Eastell, R. Leary for the National Bone Health Alliance Bone Turnover Marker Project. Use of CTX-I and PINP as bone turnover markers: National Bone Health Alliance recommendations to standardize sample handling and patient preparation to reduce pre-analytical variability. Osteoporos. Int. 2017, 28, 2541-2556. [CrossRef]

23. Garnero, P.; Grimaux, M.; Seguin, P.; Delmas, P.D. Characterization of immunoreactive forms of human osteocalcin generated in vivo and in vitro. J. Bone Miner. Res. 1994, 9, 255-264. [CrossRef]

24. Jennings, K.A.; Sheward, W.J.; Harmar, A.J.; Sharp, T. Evidence that genetic variation in 5-HT transporter expression is linked to changes in 5-HT2A receptor function. Neuropharmacology 2008, 54, 776-783. [CrossRef] [PubMed]

25. Neumaier, J.F.; Root, D.C.; Hamblin, M.W. Chronic fluoxetine reduces serotonin transporter mRNA and 5-HT1B mRNA in a sequential manner in the rat dorsal raphe nucleus. Neuropsychopharmacology 1996, 15, 515-522. [CrossRef]

26. Pineyro, G.; Blier, P.; Dennis, T.; de Montigny, C. Desensitization of the neuronal 5-HT carrier following its long-term blockade. J. Neurosci. 1994, 14, 3036-3047. [CrossRef] [PubMed]

27. Tabassum, S.; Afridi, B.; Aman, Z. Phloroglucinol for acceleration of labour: Double blind, randomized controlled trial. J. Pak. Med. Assoc. 2005, 55, 270-273.

28. Lee, J.W.; Seok, J.K.; Boo, Y.C. Ecklonia cava Extract and Dieckol Attenuate Cellular Lipid Peroxidation in Keratinocytes Exposed to PM10. Evid. Based Complement. Altern. Med. 2018, 2018, 8248323. [CrossRef]

29. Choi, H.S.; Jeon, H.J.; Lee, O.H.; Lee, B.Y. Dieckol, a major phlorotannin in Ecklonia cava, suppresses lipid accumulation in the adipocytes of high-fat diet-fed zebrafish and mice: Inhibition of early adipogenesis via cell-cycle arrest and AMPKalpha activation. Mol. Nutr. Food Res. 2015, 59, 1458-1471. [CrossRef]

30. Son, M.; Oh, S.; Lee, H.S.; Ryu, B.; Jiang, Y.; Jang, J.T.; Jeon, Y.J.; Byun, K. Pyrogallol-Phloroglucinol-6,6'-Bieckol from Ecklonia cava Improved Blood Circulation in Diet-Induced Obese and Diet-Induced Hypertension Mouse Models. Mar. Drugs 2019, 17, 272 [CrossRef]

31. Son, M.; Oh, S.; Choi, C.H.; Park, K.Y.; Son, K.H.; Byun, K. Pyrogallol-Phloroglucinol-6,6-Bieckol from Ecklonia cava Attenuates Tubular Epithelial Cell (TCMK-1) Death in Hypoxia/Reoxygenation Injury. Mar. Drugs 2019, 17, 602. [CrossRef]

32. Park, M.H.; Heo, S.J.; Kim, K.N.; Ahn, G.; Park, P.J.; Moon, S.H.; Jeon, B.T.; Lee, S.H. 6,6'-Bieckol protects insulinoma cells against high glucose-induced glucotoxicity by reducing oxidative stress and apoptosis. Fitoterapia 2015, 106, 135-140. [CrossRef]

33. Wijesekara, I.; Yoon, N.Y.; Kim, S.K. Phlorotannins from Ecklonia cava (Phaeophyceae): Biological activities and potential health benefits. Biofactors 2010, 36, 408-414. [CrossRef] [PubMed] 